\title{
Ressentimento e Eterno Retorno na série Dark
}

\author{
Resentment and Eternal Recurrence in the Dark series \\ Resentimiento e Eterno Retorno en la serie Dark \\ Marcos de Camargo VON ZUBEN ${ }^{1}$ \\ Stamberg José da SILVA JÚNIOR ${ }^{2}$
}

\section{Resumo}

Este artigo investiga, utilizando uma abordagem exploratória, o modo como os conceitos de ressentimento e eterno retorno, propostos por Nietzsche, estão presentes na primeira temporada da série original da Netflix, a produção Dark (2017). Analisa-se a relação entre as ideias do filósofo alemão e a narrativa de ficção seriada germânica a partir de uma chave imagético-discursiva que visa a concatenar os pressupostos de Nietzsche ao enredo e argumento da série. Os resultados apontam para as ideias de eterno retorno e ressentimento como alguns dos possíveis leitmotivs de Dark.

Palavras-chave: Ressentimento. Eterno Retorno. Nietzsche. Ficção Seriada. Dark.

\begin{abstract}
This article investigates, using an exploratory approach, the way in which the concepts of resentment and eternal return, proposed by Nietzsche, are present in the first season of Netflix's most successful original series, the production Dark (2017). We analyzed the relationship between the ideas of the German philosopher and the German serial fiction narrative based on an image-discursive key that aims to link Nietzsche's assumptions to the series' plot and argument. The results point to the ideas of eternal return and resentment as some of Dark's possible leitmotifs.
\end{abstract}

Keywords: Resentment. Eternal Recurrence. Nietzsche. Serial Fiction. Dark.

\section{Resumen}

Este artículo investiga, con un enfoque exploratorio, la forma en que los conceptos de resentimiento y eterno retorno, propuestos por Nietzsche, están presentes en la primera

\footnotetext{
1 Professor Adjunto IV da Universidade do Estado do Rio Grande do Norte/UERN; Doutor em Filosofia/Unicamp. E-mail: zuben@uol.com.br ORCID: 0000-0002-0390-7113.

${ }^{2}$ Doutorando do Programa de Pós-Graduação Interdisciplinar em Ciências Humanas da UFSC e mestre em Ciências Sociais e Humanas pela UERN. E-mail: stambergjunior@ gmail.com ORCID: 0000-0002-86806501.
} 
temporada de la serie original más exitosa de Netflix, la producción Dark (2017). Analizamos la relación entre las ideas del filósofo alemán y la narrativa de ficción serial alemana a partir de una clave imagen-discursiva que pretende vincular los supuestos de Nietzsche con la trama y el argumento de la serie. Los resultados apuntan a las ideas del eterno retorno y el resentimiento como algunos de los posibles leitmotivs de Dark.

Palabras clave: Resentimiento. Eterno Retorno. Nietzsche. Ficción en Serie. Dark.

\section{Introdução}

Eleita em votação popular, em 2020, com $80 \%$ dos cerca de 2,5 milhões de votos pelo site de referência em audiovisual, o Rotten Tomatoes, como a melhor série original da Netflix, Dark é uma produção alemã que reporta, direta ou indiretamente, a conceitos filosóficos, científicos, mitológicos, artísticos e literários. A série, que possui uma estrutura não linear, é marcada por uma complexidade narrativa e uma singularidade estilística que a diferencia entre as outras - não apenas pela sofisticação do enredo, mas pelo conjunto intertextual que atravessa a obra. Longe de limitarmos às múltiplas facetas que a narrativa possa apresentar, buscamos, neste artigo, uma hermenêutica exploratória que visa a relacionar aspectos da filosofia nietzschiana e a obra audiovisual.

Embora tenha alcance de nível global, Dark ainda é um objeto de estudo pouco explorado no ambiente acadêmico, o que torna a pesquisa sobre a série ainda mais relevante. Entre as produções na academia, destacamos o artigo do professor equatoriano Lenin Paredes (2019) sobre Dark, que aponta para a concepção de tempo cíclico do ponto de vista da ficção científica que a série traz no roteiro. No Brasil, a pesquisa de Vargas e Corrêa (2019) demonstra as alterações na estrutura da narrativa televisual que Dark apresenta. Trabucco (2018), por sua vez, mostra a relação espaço-tempo que a narrativa faz a partir das releituras de fatos reais, como o desastre de Chernobyl. Buscamos, assim, ampliar e contribuir para a pesquisa sobre essa narrativa de tamanho impacto do ponto de vista da recepção.

Conceitos e ideias de filósofos e pensadores não são incomuns no cinema, ainda mais em se tratando das narrativas de ficção seriada que se alimentam de influências artísticas, filosóficas, literárias, cinematográficas, sociológicas, entre outras. Sintomas do nosso tempo (JOST, 2012, p. 70), as séries possuem uma estrutura cuja potencialidade 
infinita de fios narrativos é utilizada para que o espectador se mantenha aficionado. Geralmente associadas a um certo entretenimento alienante, as narrativas de ficção seriada podem revelar aspectos estéticos e discursivos que, ao passo que divertem ${ }^{3}$, podem construir conhecimento de forma lógica e afetiva simultaneamente.

O conceito de eterno retorno de Nietzsche aparece explicitamente na série por meio dos diálogos de alguns personagens da primeira temporada de Dark (2017). Mas, conforme defendemos aqui, essa ideia vai além da linguagem discursiva, já que aparece como constituinte do enredo. O eterno retorno está diretamente ligado a um outro conceito do filósofo: o do ressentimento permeia implicitamente a produção. Assim, analisamos trechos da primeira temporada da trama na tentativa de localizar elementos narrativos, discursivos e imagéticos na diegese que apontem para as ideias de Nietzsche e estejam relacionados a um possível retorno de uma cosmovisão cíclica de mundo que permeia o imaginário contemporâneo, conforme argumenta Maffesoli (2003).

\section{Os valores ocidentais e a negação da vida}

Em A genealogia da moral, obra escrita em 1887, Friedrich Nietzsche sacode o mundo das ideias ao indagar acerca do valor dos valores. Os valores, para Nietzsche, não têm uma realidade ontológica mas são produtos do ato - demasiadamente humano - de criar. Não são fatos e nem são eternos, mas, antes, pertencentes às interpretações humanas do mundo, sendo parte da atividade criadora e destruidora, do processo orgânico da vontade de potência ${ }^{4}$.

O "bem", preconizado como o valor mais elevado pelas práticas de vida da civilização grega arcaica, que o associava à virilidade, à força, ao orgulho, à coragem, à nobreza (NIETZSCHE, 2001, p. 28-29), modifica-se por meio do que o filósofo chama de "inversão de valores" ou "transvaloração", realizada a partir da moral escrava, que

\footnotetext{
${ }^{3}$ Para o filósofo coreano Byung-Chul Han (2019), a efetividade do entretenimento que agrada também se dá no âmbito cognitivo, no âmbito do sentido, pois "faz com que significados e valores circulem pelo caminho narrativo e emotivo" (HAN, 2019, p. 141).

${ }^{4}$ Para Nietzsche, a vontade de potência está associada à força motriz presente em tudo o que está vivo. Nietzsche acredita que a vontade de potência busca a expansão de cada ser em um processo de constante autossuperação. "Esse mundo é a vontade de potência - nada além disso! E também vós próprios sois essa vontade de potência - nada além disso!” (NIETZSCHE, 1978, p. 36).
} 


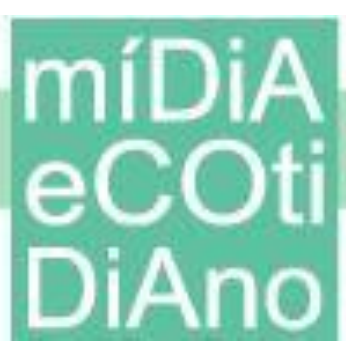

passa a ser a base da civilização ocidental com a solidificação do cristianismo. Aquilo que outrora era denominado por "bem”, no universo judaico-cristão é considerado "mal”, estando este ligado ao mundo sensível; enquanto o primeiro, ao inteligível.

Os valores que se impõem passam a ser a abnegação, a fraqueza, a humildade, o altruísmo. A dicotomia maniqueísta torna-se a característica da moral e da cultura ocidental - algo que, para o filósofo, parece não ter se modificado mesmo com o advento da modernidade e sua pretensa crença na ciência, no progresso e no homem como centro e medida das coisas. Para Nietzsche, o que a modernidade realizou não foi a ruptura com os valores metafísicos e conceituais, mas apenas a secularização destes.

Essa transvaloração dos valores acaba por gerar, em nível individual e social, sujeitos cuja interiorização afetiva torna-os pertencentes ao espírito do ressentimento, que em Nietzsche desempenha um papel muito peculiar na construção de sua filosofia (PASCHOAL, 2008), perpassando temas centrais tais como a crítica à cultura, à religião, à moral e até mesmo às configurações políticas e ideológicas, como o socialismo e a democracia.

O termo, cuja origem está na língua francesa e remonta ao século XVI, deriva do verbo "ressentir", significando a possibilidade de reviver uma sensação ou sentimento anteriormente experimentados. Na filosofia nietzschiana, o ressentimento passa a ser associado à ideia de autoenvenenamento, uma espécie de constelação afetiva composta por sentimentos como inveja, rancor, ódio, raiva, tristeza, mesquinhez e vingança imaginária. É, na verdade, um tipo de resposta reativa que se apresenta a um estímulo que não é apenas sentido, mas ressentido, “ou que continua sendo sentido mesmo quando ele já não existe mais, ao menos externamente, pois, internamente (no subterrâneo daquele homem) permanece produzindo seus efeitos" (PASCHOAL, 2008).

\section{Ressentimento e negação do presente}

Resultando em efeitos negativos de ordem psicofisiológica, o ressentimento se origina no retorno dos desejos vingativos sobre o eu, que não daria espaço, segundo Nietzsche (2000, p. 47), para "um pouco de sossego, um pouco de tábula rasa da consciência, para que novamente haja lugar para o novo". 
Segundo a psicanalista Maria Rita Kehl (2011, p.23), o ressentimento é a fermentação da crueldade adiada e "transmutada em valores positivos, que envenena e intoxica a alma", que fica eternamente condenada a não esquecer. Essa constelação afetiva relega a força ativa do esquecimento - que para Nietzsche é sinônimo de saúde ao ostracismo, em detrimento de sua faculdade oposta, a memória, já que "forte é aquele que possui uma força plástica de esquecimento e assimilação mais inteira, mais organicamente sadia" (GIACÓIA JÚNIOR, 2001, p. 85).

A memória é caracterizada, não por um simples "não-poder-livrar-se" da impressão uma vez recebida na consciência, mas sim por um ativo "não-querer-livrar-se" e prosseguir querendo o que já está no passado. Nessa longa cadeia do querer, o homem do ressentimento fica preso ao passado e ausente nas experiências presentes, visto que "nelas não temos nosso coração, para elas não temos ouvidos" (NIETZSCHE, 2000, p.46).

Para o filósofo, a memória nos limita aos acontecimentos pregressos, tornandoos indeléveis em nossa consciência. Provocando a inibição da nossa força, da ação correspondente a cada momento, a memória apequena-nos à dor e ao medo de partir para o desconhecido, o novo. Ela não nos deixa experimentar o risco: aquele que é capaz de nos fazer sair da zona de conforto de nós mesmos.

Segundo o filósofo, o que nos transtorna não é o sofrimento humano em si, mas antes a ausência de sentido deste. Por não sabermos lidar com a vida assim como ela é, construímos a cristalização da ideia da verdade e fechamos quaisquer frestas de expansão da vontade de potência (ou pelo menos a inibição da expansão da força) e paralisamos nas cores sombrias de nossa existência, no lado obscuro do ser.

Ao abrirmos espaço para a memória, o passado nos alcança e reflui dentro de nós, tornando a dor "o mais poderoso auxiliar da mnemônica" (NIETZSCHE, 2000, p. 43). É como se o que passou não se esvaísse, mas permanecesse obstruindo o presente e impedindo o futuro em sua máxima plenitude. Nesse estado geral de morbidez, o sujeito do ressentimento, incapaz de esquecer, sofre incessantemente recordando de forma pungente suas experiências desagradáveis, em um círculo vicioso de declínio afetivo e fisiológico (BITTENCOURT, 2011).

Nietzsche argumenta que os ressentidos são sofredores que fruem a própria desconfiança, acarretando em prejuízos para si mesmos. Para o autor, esses tipos 


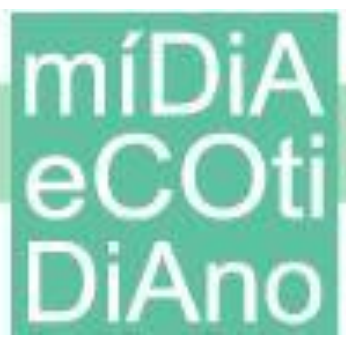

revolvem as vísceras de seu passado e seu presente "atrás de histórias escuras e questionáveis, em que possam regalar-se em uma suspeita torturante, e intoxicar-se de seu próprio veneno de maldade" (NIETZSCHE, 2000, p. 117).

Sendo a memória, para o autor, uma reprise do ontem, o ressentido torna-a uma barreira para afirmar a vida como tal. Sintetizando-se em uma estanque característica de si, o sujeito do ressentimento nutre na memória uma intensa força afetiva anteriormente experimentada, que gera inércia e impede a capacidade deste de autossuperar-se e seguir adiante, já que, nos termos do autor, a vida é movimento.

Assim, não conseguindo digerir os sentimentos e vivendo em uma culpa contínua, o sujeito do ressentimento impede a força voraz do esquecimento, elemento fundamental para viver a vida em toda a sua potência. Sem o esquecimento, não poderia haver felicidade, jovialidade, esperança e orgulho, argumenta Nietzsche (2000).

\section{O eterno retorno e o sim à vida}

O Sim à vida, fundamental para a experiência desta em sua máxima potência e intensidade, implica justamente ressignificar o passado e as dores a partir do entendimento destes como peças-chave para o fortalecimento do sujeito. "É uma fórmula da suprema afirmação, um dizer 'sim' sem reservas, mesmo ao sofrimento, mesmo à culpa, mesmo a tudo o que é problemático e estranho na existência” (DIAS, 2011, p. 34).

Redimir-se e ir além da memória e do ressentimento implica a compreensão do sofrimento como inerente à condição humana: é na superação de si que o homem tornase aquilo que é. Para isso, é preciso entender que somos responsáveis pela nossa própria existência, que uma censura pelo fracasso na vida deve valer só para nós, não para qualquer força superior. "Não precisamos da fantasia do mundo supraterreno, pois a tarefa de nos tornarmos um ser humano é o realmente inaudito" (SAFRANSKY, 2011, p. 31).

Nesse sentido, o esquecimento é condição natural de um ser humano que assimila e digere de forma ativa as suas experiências. É a ponte para a compreensão de uma vontade de potência afirmativa do instante-agora. Para que isso aconteça, segundo Nietzsche, um outro modo de conceber a temporalidade, que não seja por meio da linearidade - já que esta é a manifestação principal do ressentimento e do espírito de 
vingança contra a vida (MECA, 2013, p.188) - pode ser um caminho para a redenção do ressentimento.

A percepção de um tempo linear que a modernidade se fixou está proposta na expectativa pelo futuro, pelo progresso e que por um telos (o olhar fixo no ulterior, a negação do poder do instante). Simultaneamente, a linearidade gera um passado saudoso, no qual, reviver as feridas na memória é mais seguro do que abrir-se para o risco de viver o presente. Nietzsche, então, propõe o conceito de Eterno Retorno.

Em linguagem metafórica, o filósofo trágico aponta para a imagem de um universo que assombra conforme seus ciclos: uma vida que pode vir a repetir-se infinitamente. A ideia do autor é a de que isso se torne um imperativo existencial, uma afirmação incondicional do aqui-agora. O ponto crucial em sua filosofia é que possamos nos servir do potencial criador/destruidor do momento presente a fim de que a vida se torne uma obra de arte - uma espécie de criação de si mesma intensificada por um ativo querer dessa existência da forma como ela se apresenta.

Em várias passagens, mas principalmente no aforismo 341 de A gaia ciência, intitulado "O peso mais pesado", Nietzsche (2013) revela quão surpreendente poderia ser para todos nós o retorno dessa mesma vida: amaríamos a nossa condição ou amaldiçoaríamos a nossa existência?

E se um dia, ou uma noite, um demônio te seguisse em tua suprema solidão e te dissesse: "Esta vida, tal como a vives atualmente, tal como a viveste, vai ser necessário que a revivas mais uma vez e inumeráveis vezes; e não haverá nela nada de novo, pelo contrário! A menor dor e o menor prazer, o menor pensamento e o menor suspiro, o que há de infinitamente pequeno em tua vida retornará e tudo retornará na mesma ordem - essa aranha também e esse luar entre as árvores e esse instante e eu mesmo! A eterna ampulheta da vida será invertida sem cessar - e tu com ela, poeira das poeiras!" Não te jogarias no chão, rangendo os dentes e amaldiçoando esse demônio que assim falasse? Ou talvez já viveste um instante bastante prodigioso para lhe responder: "Tu és um deus e nunca ouvi coisa tão divina!" Se este pensamento te dominasse, tal como és, te transformaria talvez, mas talvez te aniquilaria; a pergunta: "queres isso ainda uma vez e um número incalculável de vezes?", esta pergunta pesaria sobre todas as tuas ações como o peso mais pesado! E então, como te seria necessário amar a vida e a ti mesmo para não desejar mais outra coisa que essa suprema e eterna confirmação, esse eterno e supremo selo! (NIETZSCHE, 2013, p. 338). 
A ideia de viver essa mesma vida durante a eternidade é uma hipótese que, para o pensador, poderia ser considerada como potencialidade para a plenitude e intensidade desta existência: fazer o indivíduo considerar como elemento fundamental cada dor, cada alegria: considerar o instante-já como extraordinário. Para Nietzsche, esse conceito vai além de um imperativo existencial, admitindo-o como possibilidade cosmológica para o funcionamento cíclico do universo. Nesse sentido, o devir temporal, que seria infinito, estaria diretamente ligado à matéria finita do universo - disso resultando o inevitável processo de repetição presente nos ciclos da natureza, como o movimento dos astros, as estações do ano, entre outros.

Sendo um filósofo trágico, Nietzsche (2013) toma a concepção de destino dos gregos e o faz a partir do eterno retorno. Para o pensador, é justamente quando aceitamos nosso destino e o amamos - independente de como ele se apresenta - que nos tornamos demasiadamente humanos. É a partir disso que nasce o conceito de Amor-Fati, o amor ao destino. Não amar o destino, não amar esta vida e negá-la é viver em ressentimento.

Nietzsche acredita que "a gente perde mui facilmente o olhar correto para aquilo que a gente fez quando o desfecho é ruim: um sentimento de culpa me parece uma espécie de 'olhar maldoso'. Guardar na honra aquilo que acaba dando errado, tanto mais pelo fato de ter dado errado" (NIETZSCHE, 2000, p. 43).

Amar ao destino significaria entender que nem todas as experiências são da ordem do aprazível, mas que mesmo a doença, a morte, o infortúnio e o sofrimento servem como estímulos à vida. A aceitação integral dos aspectos mais cruéis da existência é da ordem do heroico - mas acessível a qualquer indivíduo que saiba assimilar o esquecimento como força reguladora da digestão psíquica. Isso, para o filósofo, é a afirmação trágica da vida.

Pensador do contemporâneo, Michel Maffesoli (2003, p.9) não apenas corrobora com as ideias de Nietzsche, como considera que a "passagem de um tempo monocromático, linear, seguro, o do projeto, a um tempo policromático, trágico por essência, presenteísta e que escapa ao utilitarista do cômputo burguês" é característica da vida contemporânea. Essa maneira de percepção de tempo, que outrora acreditávamos relegada aos valores arcaicos e obscuros, permanece ativa no imaginário coletivo. 
O sociólogo francês argumenta que o trágico é um não-dito ensurdecedor, algo empiricamente vivido no cotidiano, marcado por aquilo que chama de reencantamento do mundo, pois "os videoclipes, a publicidade, os jogos de informática, as diversas formas de 'ciberespaço' o mostram de sobra: entramos, novamente, no tempo do mito" (MAFFESOLI, 2003, p.14).

Como veremos na análise sobre a série, a negação da fortuna a que estão destinados os personagens e o retorno infinito de circunstâncias e situações parece ser a base do enredo da narrativa - que apresenta a irreversibilidade da mudança do tempo cíclico, do passado e daquilo que já foi vivido. "A vontade não pode querer para trás; não pode quebrantar o tempo e o apetite do tempo - eis a solitária aflição da vontade”, diria Nietzsche (2006, p. 133) em seu Zaratustra.

\section{Dark: uma narrativa de memórias e cicatrizes}

A primeira temporada de Dark é protagonizada por Jonas Kahnwald (Louis Hoffmman) que aos 16 anos vivencia a perda do pai, Michael Kanhwald (Sebastian Rudolph), morto em suicídio. Sem conseguir lidar com a dor de seu sofrimento, Jonas é atormentado primeiramente pelos demônios das lembranças do pai e depois pelo desaparecimento de seu amigo Mikkel Nielsen (Daan Liebrenz). O sumiço de Mikkel é o segundo de uma sequência de casos que acontecem na cidade de Winden ${ }^{5}$, na Alemanha, após 33 anos sem nenhuma ocorrência semelhante. A localidade - que abriga moradores repletos de segredos e não ditos (ressentidos), presos em suas dores do passado - possui uma usina nuclear cujo subterrâneo é marcado por cavernas.

Nas grutas, é possível encontrar um portal (em cuja entrada está escrito "Sic Mundus Creatus Est" em latim, ou "Assim o Mundo foi Criado") que pode levar o viajante 33 anos antes ou depois da data em que se encontra. Jonas descobre o mapa das cavernas, recebendo a ajuda oculta do personagem inicialmente chamado de Estrangeiro (Andreas Pietschmann), o qual na verdade é o seu eu 33 anos mais velho. Assim, parte

\footnotetext{
${ }^{5}$ Em alemão o verbo Winden significa ligar, enrolar, um ligar que dá volta, serpentear, enrolar uma fita em volta de algo. No reflexivo, pode significar contorcer-se. Nesse sentido, interpretamos aqui que a série parece querer revelar que as pessoas dessa cidade estão envoltas em um círculo infinito do qual não podem escapar.
} 


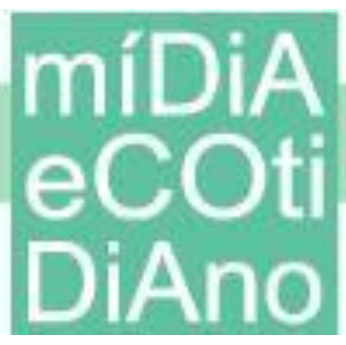

em busca de Mikkel, que havia sumido próximo às cavernas. Ali, Jonas viaja do ano de 2019 ao de 1986 e descobre que seu amigo está vivendo naquele tempo.

Avista-o de longe, mas quando tenta se aproximar dele o Estrangeiro aparece e explica que, na verdade, Mikkel cresceria: em 1986, se casaria com Hannah (Maja Schone) - mãe do Jonas - e se tornaria seu pai, o Michael. Impactado com o que acabara de ouvir, o adolescente entra em um estado de tristeza cada vez maior por não conseguir aceitar seu destino, já que a notícia também implicaria o fim de um possível romance com Martha Nielsen (Lisa Vicari), irmã de Mikkel e, agora, tia do próprio Jonas; e também resultaria na exclusão da sua existência, já que, se levasse o pai, enquanto criança, de volta para 2019, ele não conheceria sua mãe e ambos não teriam tido o próprio Jonas.

Ainda assim, inconformado com o seu passado e sem conseguir aceitar tal como foi, Jonas volta às cavernas para tentar salvar o pai, mesmo que isso representasse a morte de si. No entanto, acaba sendo surpreendido por Noah, que o prende no bunker e por meio de uma máquina do tempo o faz viajar até 2052, o que o impede de voltar à época em que estava. Nos outros núcleos da narrativa, o policial Ulrich Nielsen (Oliver Masucci) - pai de Mikkel e, portanto, avô de Jonas, que já havia vivido o desaparecimento de seu irmão Mads Nielsen (Valentim Oppermann) quando criança -, agora também parte em busca do filho nas cavernas.

O personagem encontra o portal e viaja 66 anos antes de 2019, ou seja, em 1953. Acreditando que o culpado pelo sumiço das crianças era Helge Doppler (Hermann Beyer), Ulrich o ataca enquanto ele ainda era uma criança, naquele ano. Convicto da morte de Helge, Ulrich tenta voltar a seu tempo acreditando que o falecimento do garoto evitaria o fato de, no futuro, Helge sequestrar seu filho e os outros desaparecidos. No entanto, Helge fica apenas gravemente ferido e Ulrich é preso no tempo (em 1953) e encarcerado na prisão pelo policial Egon Tiedemann (Sebastian Hulk), acusado pelo crime que acabara de ter cometido.

Egon é pai de Claudia Tiedemann, a qual em 1953, quando criança, dá aulas a Helge e em 1986 é a presidente da usina. Ao assumir o cargo de liderança do estabelecimento industrial, Claudia começa a desconfiar das atividades nucleares daquele lugar, já que os números divulgados não correspondem à quantidade de energia nuclear utilizada ali (muito superior). Claudia é mãe de Regina Tiedemann: em 1986, uma 


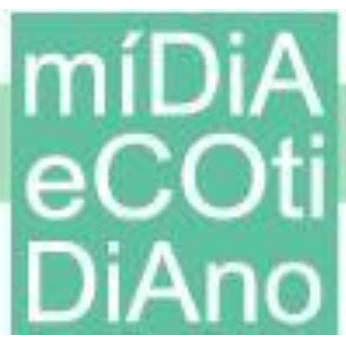

adolescente que sofre com a pressão da genitora e com o bullying dos colegas de classe. Dentre eles, Ulrich e Katharina Nielsen (no futuro, pais do Mikkel e avós do Jonas), que atacam Regina acreditando que ela havia contado à Polícia que o rapaz havia estuprado a namorada, quando na verdade Hannah (no futuro, mãe de Jonas, viúva de Michael) o havia feito, já que sempre foi apaixonada por Ulrich e visava a destruir o relacionamento dele com Katharina.

Enquanto estava sendo atacada, Regina é defendida por Aleksander, seu futuro marido. Juntos, eles terão um filho chamado Bartosz. Em 2019, Ulrich e Hannah mantêm um caso extraconjugal que acaba sendo descoberto por Katharina, gerando um clima de tensão entre os três. Nesse mesmo ano, Ulrich, em busca de seu filho e antes de ficar preso no tempo, vai ao hotel do qual Regina é proprietária. Ela, injustiçada e ressentida por anos pelo fato de ele nunca ter lhe pedido desculpas pelo ataque em 1986, conta para Ulrich quem havia feito a denúncia que o havia levado a ser preso quando jovem: a própria Hannah, sua amante.

A filha de Ulrich, Martha, namora com o filho de Regina, Bartosz, mas é apaixonada por Jonas, seu sobrinho (eles, no entanto, não sabem que são parentes: só saberão, justamente, quando revistarem o passado). Bartosz descobre o sentimento entre os dois quando Noah se aproxima e lhe conta. Noah se apresenta como um reverendo que mostra a Bartosz que conhece tudo o que estava acontecendo e que aconteceria no futuro. O homem é responsável pelo desaparecimento das crianças: ele se utiliza de uma máquina do tempo para isso, fazendo com que o ciclo se repita.

A série, portanto, acompanha as fraturas dolorosas das famílias Doppler, Kahnwald, Tiedemann e Nielsen, imersas em seus segredos, não ditos, ressentimentos e na negação da vida diegética enquanto tal. Presos em uma teia de feridas que não cicatrizam, os personagens tentam alterar o passado ou o futuro acreditando que assim a vida ficaria melhor - algo caro na filosofia nietzschiana: a impossibilidade de alterar o que passou, mas de ressignificar o histórico de modo que este auxilie a vida no presente. O ressentimento, assim, parece ser o afeto básico de boa parte das ações dos personagens na série, os quais, por não conseguirem lidar com suas dores, tentam recriar ou alterar o que se passou. 


\section{Winden: uma cidade enrolada em feridas abertas}

A ligação do município de Winden com uma teia de feridas abertas é feita, justamente, pela debilidade psicofisiológica contida na metástase de um ressentimento presente em personagens que não se escutam, que não buscam a si: que adoecem em suas obscuridades. Mas também é fruto de uma Winden que torna repetidamente o momento presente como algo intolerável.

Há um laço temporal que atravessa Winden, nascido de um incidente na usina nuclear, no verão de 2019, provocado por um buraco de minhoca criado a partir de impulsos gravitacionais. A energia desse incidente é canalizada entre as cavernas da cidade e utilizada como um portal para viajar no tempo. Na primeira temporada, Noah e Helge também se utilizam dessa energia, a qual permite que sequestrem as crianças e as levem mortas para outro tempo: sempre 33 anos para a frente ou para trás $(1953,1986,2019)$.

Uma das crianças desaparecidas é, justamente, Mikkel Nielsen. O desaparecimento do garoto, que viaja no tempo de 2019 para 1986 e fica preso ali até se transformar em Michael Kahnwald, é o ponto nevrálgico do enredo na primeira temporada. A partir disso, todos os fatos que se encadeiam em causa e efeito entrelaçamse e expõem o subterrâneo de uma Winden que revive o seu passado ciclicamente, ordenando-o com o presente e o futuro.

Em dois momentos, a conexão da cidade com uma doença é realizada. No sexto capítulo, Katharina Nielsen liga para a rádio local, após o desaparecimento do filho, a fim de expor sua indignação com o ocorrido e também emergir o inaudito entre os moradores (Figura 1). Segue trecho:

Katharina: Quero que as pessoas finalmente entendam o que acontece aqui. Estamos todos cegos. Há um assassino entre nós. Ninguém ousa dizer isso. Mas é a verdade. Nos agarramos à esperança de que isso nunca aconteceria aqui. Todos nos conhecemos. Achamos que sabemos tudo sobre o outro. Mas será verdade? Somos vizinhos de pessoas cujas vidas não sabemos nada. E por trás de uma dessas portas está meu filho. Pode ser qualquer uma. A do caixa do mercado. Ou um convidado de domingo, que brinca com nossos filhos. Não quero mais fechar os olhos. E vocês deveriam fazer o mesmo. Esta cidade está doente. Winden é como um câncer. $\mathbf{E}$ todos fazemos parte disso ( $D A R K$, 2017, Temporada 1, Episódio 6, grifo nosso). 
Figura 1 - Katharina em conexão com a rádio da cidade

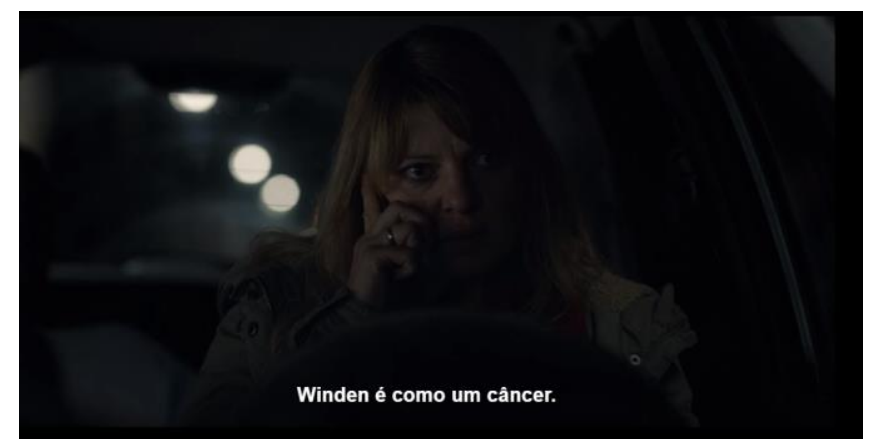

Fonte: Dark, Temporada 1, Episódio 6.

No oitavo capítulo da série, o personagem chamado de Estrangeiro (que, na verdade, é o Jonas de meia-idade) conversa com o relojoeiro-cientista H.G. Tannhaus. No diálogo, é ressaltada a ligação Winden e uma gigantesca ferida cancerosa (Figura 2). E, claro, o desejo do Estrangeiro em querer destruir o curso dos eventos e reorganizar a linha do tempo. O ressentimento se manifesta, então, como uma negação da vida no próprio espaço diegético da narrativa.

Figura 2 - O Estrangeiro em conversa com H.G.Tannhaus

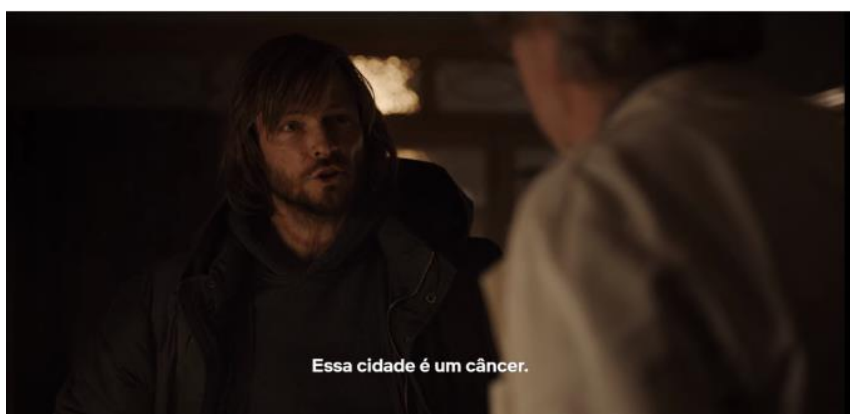

Fonte: Dark, Temporada 1, Episódio 8.

Tannhaus: Este aparelho possibilita que alguém viaje no tempo? Ele cria um buraco de minhoca?

Estrangeiro: Ele abre um portal para viajar 33 anos para o passado e 33 anos para o futuro.

Tannhaus: E o buraco de minhoca pelo qual veio? Foi o aparelho que criou?

Estrangeiro: Não. Poucos meses atrás um incidente na usina nuclear gerou uma explosão de energia. $\mathrm{O}$ aparelho consegue repetir o mesmo processo.

Tannhaus: E você quer criar outro buraco de minhoca?

Estrangeiro: Não, quero destruir o que existe.

Tannhaus: Quero que vá embora. 
Estrangeiro: Esta cidade é um câncer. Todos fazemos parte, mas posso mudar isso. Seu aparelho pode mudar isso.

Tannhaus: Saia.

Estrangeiro: Eu vi o futuro. Sei o que vai acontecer. Preciso consertar as coisas e o senhor precisa me ajudar $(D A R K, 2017$, Temporada 1 , Episódio 8, grifos nossos).

Ao apresentar a máquina do tempo ao H.G. Tannhaus, o Estrangeiro aponta para o relojoeiro como o inventor do aparelho. A construção do aparato ocorre em 1953, quando a personagem Claudia Tiedemman, mais velha, encontra o cientista e pede que construa tal máquina, afirmando que o invento servirá para alterar os acontecimentos que já ocorreram.

Tannhaus: Posso ajudar? Na verdade, nós estamos fechados.

Claudia: Acho que tenho algo que lhe interessa. Quero que construa isso para mim.

Tannhaus: O que é isso?

Claudia: É algo que consertará a linha do tempo (DARK, 2017, Temporada 1, Episódio 9, grifo nosso).

\section{Figura 3 - Claudia Tiedemann conversa com H.G.Tannhaus}

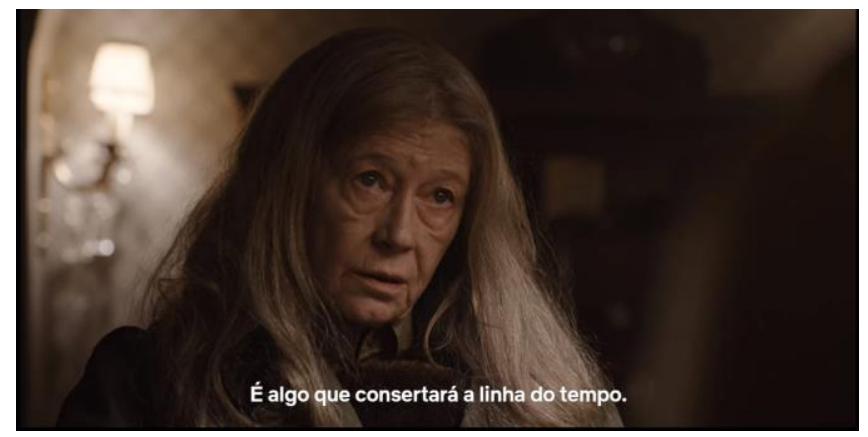

Fonte: Dark, Temporada 1, Episódio 9.

O fato de a cidade apresentar-se, no espaço diegético da narrativa, como limitada a uma condição mórbida, revela o caráter doentio de feridas e cicatrizes oriundas de personagens que preferem "consertar" a linha do tempo (Figura 3) a assumir o risco do instante-extraordinário, do presente. Para Nietzsche, o que precisamos é de uma saúde em que a redenção do passado e a contingência do futuro sirvam como auxílios para estar na vida presente com intensidade dionisíaca, "uma saúde que a gente não apenas tem, mas adquire e tem de adquirir constantemente, porque sempre se volta a abandoná-la" (NIETZSCHE, 2003, p. 113). 
Nesse sentido, o instante, caracterizado por sua estrutura instável em que todas as possibilidades têm ensejo, é aquele que mergulha o indivíduo além das linguagens, virtualidades e planejamentos, tornando-o ativo e sadio. A criação e a destruição trágica do instante presente torna o corpo vigoroso, saudável, visto que este é acionado para o perigo da instabilidade e do risco. Enquanto o ressentimento faz parte de um certo adoecimento do desejo pela vida, pois a nega, a saúde está no sentido afirmativo da existência, "afirmativo até a justiça, até a salvação, inclusive de tudo aquilo que passou" (NIETZSCHE, 2003, p. 125).

\section{Atribuição do infortúnio à alteridade}

Uma das facetas do ressentimento, como nos apresenta Nietzsche, é a sua estrutura sedimentada no espaço da queixa. Os sujeitos ressentidos costumam atribuir a culpa dos insucessos e das adversidades à alteridade, seja ela transcendente seja imanente. Em Dark, o destino trágico dos personagens revela indivíduos que, insatisfeitos com o curso das coisas, acusam a contingência ou o outro por acontecimentos que estariam (ou não necessariamente) sob sua responsabilidade.

Após os eventos adversos ocorridos na cidade, Ulrich e Hannah, que mantinham uma relação extraconjugal, terminam o relacionamento. Apaixonada por Ulrich desde muito jovem, Hannah, cuja profissão é massagista, vai até o seu cliente, Aleksander Tiedemman, e se utiliza da chantagem para que este destrua a vida do ex-amante. Enquanto massageia Aleksander, Hannah mostra uma sacola ao presidente da usina, que logo reconhece o objeto.

O conteúdo da sacola, guardado por Hannah desde 1986, era composto de um passaporte e uma arma e havia sido escondido na floresta por Aleksander, que escondia sua verdadeira identidade para recomeçar em Winden quando mais jovem. Segue trecho do diálogo:

Aleksander: O que você quer?

Hannah: Por que alguns têm tudo e outros não têm nada? Por que você e Regina têm uma linda casa e eu nem consigo pagar minha conta de luz? Por que o destino é bom para uns e ruim para outros? Aleksander: Quer dinheiro? 
Hannah: Não quero nenhum tostão. Quero que me faça um favor. Quero que destrua Ulrich. Quero que ele perca tudo. Tudo (DARK, 2017, Temporada 1, Episódio 9, grifos nossos).

Ao tentar realizar uma vingança por não aceitar o fim do relacionamento e, simultaneamente, queixar-se acerca de seus infortúnios ao passo que inveja a vida do outro (Figura 4), Hannah manifesta características próprias da constelação afetiva do ressentimento, tal como Nietzsche o concebe.

Figura 4 - Hannah chantageia Aleksander

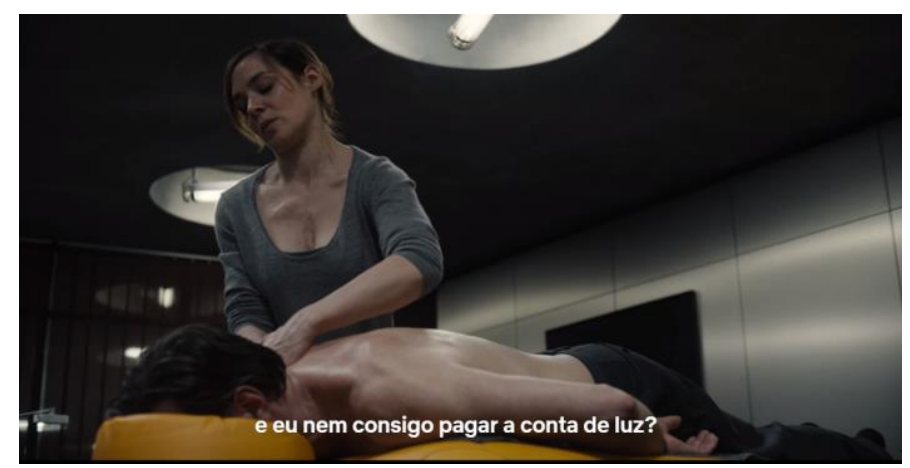

Fonte: Dark, Temporada 1, Episódio 9.

O próprio Ulrich, entretanto, que Hannah achava estar numa situação vantajosa também parecia estar insatisfeito com sua vida da forma como ela se apresentava, mesmo antes do desaparecimento do seu filho Mikkel. No primeiro capítulo da temporada, ao conversar com sua colega de trabalho Charlotte sobre a primeira desaparição em 2019, Ulrich manifesta sinais de que sua existência, tal qual estava, não o agradava.

Charlotte: Por que tem tanta certeza de que Erik fugiu?

Ulrich: Aqui é Winden. Nada acontece aqui.

Charlotte: Mas nem sempre foi assim.

Ulrich: Isso não tem nada a ver com o que aconteceu com o meu irmão.

Nada.

Charlotte: Sua mãe ligou para o número da emergência de novo. Talvez devesse visitá-la.

Ulrich: Às vezes se pergunta quando pegou o caminho errado? Quando sua vida virou o extremo oposto do que sempre desejou? (A cena acaba sem que Charlotte responda) (DARK, 2017, Temporada 1, Episídio 1, grifos nossos). 
Figura 5 - Ulrich em conversa com Charlotte

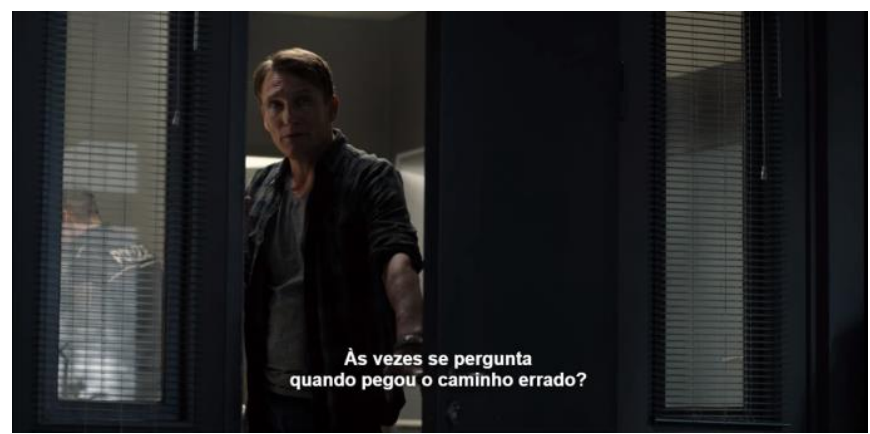

Fonte: Dark, Temporada 1, Episódio 1.

A insatisfação com o próprio status quo (Figura 5) não constitui em si o ressentimento, embora possa apresentar-se como um (des)caminho que possa desaguar naquela constelação afetiva. Estar insatisfeito, pelo contrário, pode revelar traços de que a mudança interna e saudável possa vir a ocorrer.

Não é o caso de Ulrich e dos demais personagens. Se, no momento que falava com Charlotte, a vida do policial ainda não havia passado pelas adversidades vindouras, no quarto capítulo, após o desaparecimento do filho, a insatisfação se une a afetos como indignação, raiva, desprezo, tristeza e queixa ressentida. Em conversa com a chefe, após ter invadido a usina para procurar o filho, Ulrich se expõe:

Charlotte: Tem sorte que Aleksander não prestará queixa. Todos entendem sua situação. Todos. Mas invadir a usina?

Ulrich: Que bom que entendem. Obrigado. Mas não é o suficiente. Meu filho sumiu, está bem? Não é só um arquivo na mesa. É o meu filho. Por que meu Mikkel? Fico me perguntando isso. Por que meu filho? Por que não o filho dele? Por que não? É uma punição. Quero mais é que se fodam vocês e sua compreensão. Cadê o mandado de busca? Por que ninguém faz nada? Quer saber por quê? Porque não é o filho dele. Porque não é o seu. Pare, quero descer. Pare o carro! (DARK, 2017, Temporada 1, Episódio 4, grifos nossos). 
Figura 6 - Ulrich queixa-se de seu infortúnio

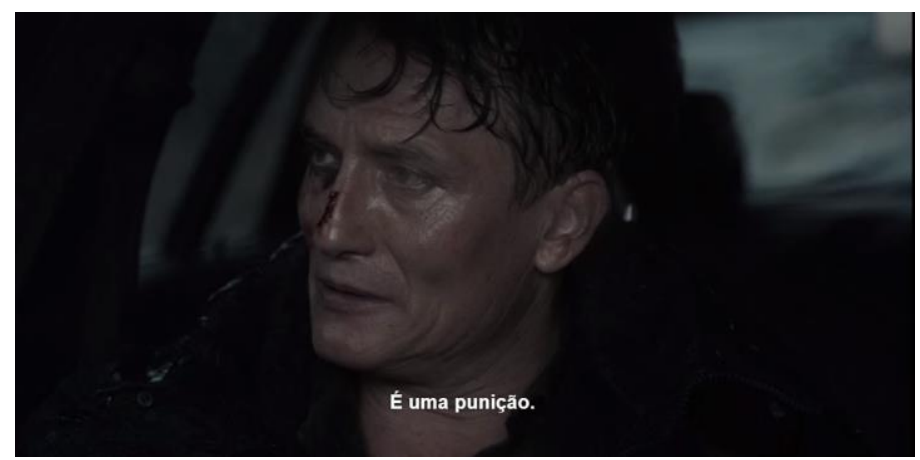

Fonte: Dark, Temporada 1, Episódio 4.

Sentir-se punido (Figura 6) pela brutal contingência que o atinge é um sinal claro de ressentimento. Embora a dor do desaparecimento de um filho seja irreparável, acreditar que está recebendo um castigo e somar ao declínio de sua sorte queixas ao outro por não passar pelo mesmo sofrimento que o dele, torna o processo ainda mais pungente e ressentido. Ulrich, então, revira todo o passado e pensa nos acontecimentos precedentes que ocorreram 33 anos antes de 2019. Em 1986, seu irmão, Mads Nielsen, também desaparecera quando criança: o ciclo parece se repetir.

A última pessoa a encontrar com o familiar de Ulrich havia sido Regina Tiedemann. O policial, então, vai até o hotel que pertencia a Regina para que possam conversar. As várias faces do ressentimento presente em ambos os personagens parecem se mostrar nessa conversa de forma reveladora. O diálogo entre eles ocorre no sexto capítulo:

[...] Ulrich: O que aconteceu na floresta foi uma brincadeira, éramos crianças. Todos erramos.

Regina: Mas você nunca pediu desculpas.

Ulrich: Então é isso que importa? É assim que se vê? Uma vítima, a coitada e inocente Regina. Você é tão falsa que me dá nojo. Você disse para o bêbado inútil do seu avô que eu estuprei Katharina.

Regina: Eu acusei você de estupro? É isso que achava?

Ulrich: Hannah viu você na delegacia.

Regina: Hannah? A mesma que aos 14 anos era tão apaixonada por você que faria de tudo para ficar com você. Acho que isso não mudou nada. Por todos esses anos pensou que eu havia feito a denúncia? Por que eu faria isso? Não sou tão ruim como você (Ulrich vai embora) (DARK, 2017, grifos nossos). 
Figura 7 - Regina discute com Ulrich

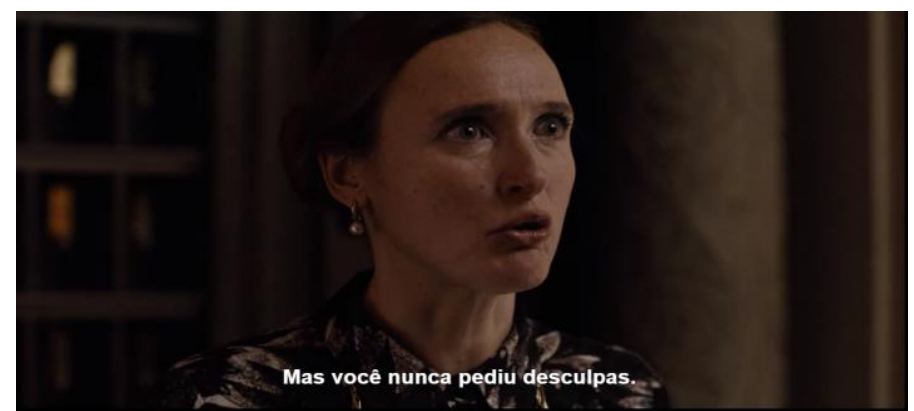

Fonte: Dark, Temporada 1, Episódio 6.

O ressentimento aparece tanto nas palavras de Regina (Figura 7), que sem a característica sadia do esquecimento e do perdão guarda seu trauma como um peso na memória, como na de Ulrich, que ao atribuir a Regina o papel de vítima acaba por espelhar-se a si próprio, visto que também se sente castigado ou vitimizado pelo desaparecimento do filho.

\section{O eterno retorno, $o$ ciclo das coisas e a vida no presente}

A série se utiliza de elementos narratológicos, diegéticos e imagéticos (Figuras 8,9 e 10) que apontam, por meio da circularidade, a acontecimentos que voltam à baila de 33 em 33 anos devido ao ciclo solar-lunar 6 .

Figura 8 - A policial Charlotte investiga os desaparecimentos em 2019/ O policial Egon

\section{Tiedemann investiga os desaparecimentos em 1986}

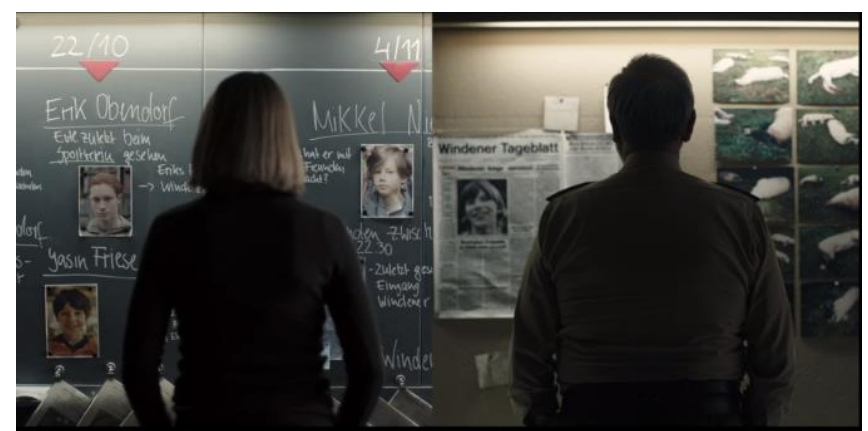

Fonte: Dark, Temporada 1, Episódio 5.

\footnotetext{
${ }^{6}$ Ao apresentar o ciclo solar-lunar, a série afirma, hipoteticamente, que o sol se alinha, em uma sequência de 33 anos, aos outros astros da galáxia, trazendo o retorno do que havia se passado ao ponto inicial. Isso interfere sobremaneira no espaço diegético da narrativa, já que a repetição é uma das marcas da série. Como veremos adiante, embora associe esse pressuposto a outros pressupostos científicos comprovados, o conceito referido, da forma como é apresentado, não tem base científica, estando presente apenas no campo da ficção e do imaginário ocidental.
} 


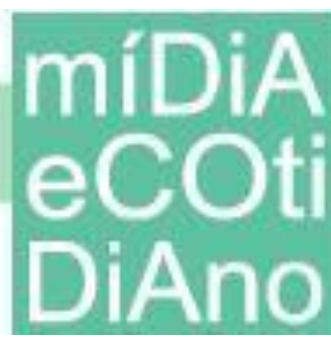

\section{PPGMC}

Figura 9 - A enfermeira Ines Kahnwald cuidando de Mikkel em 1986/Ines lendo, em 2019, o livro que dera ao garoto 33 anos antes

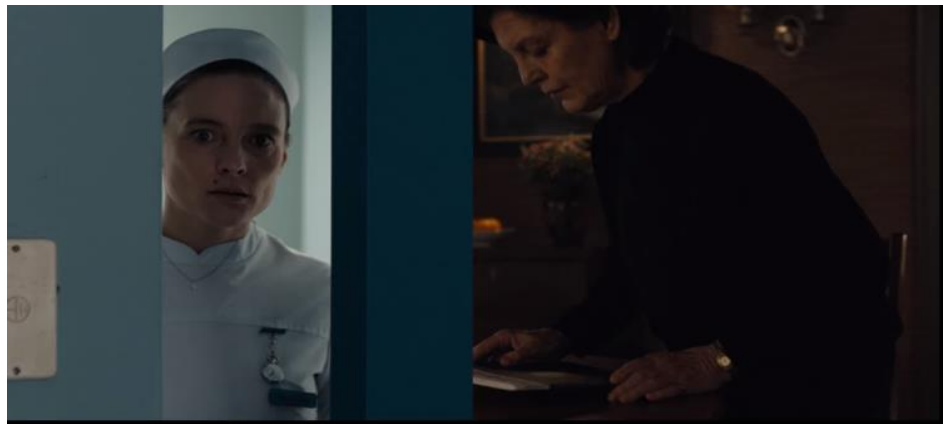

Fonte: Dark, Temporada 1, Episódio 5.

Figura 10 - Hannah apaixonada por Ulrich em 1986/Chamadas perdidas de Hannah no celular do policial em 2019

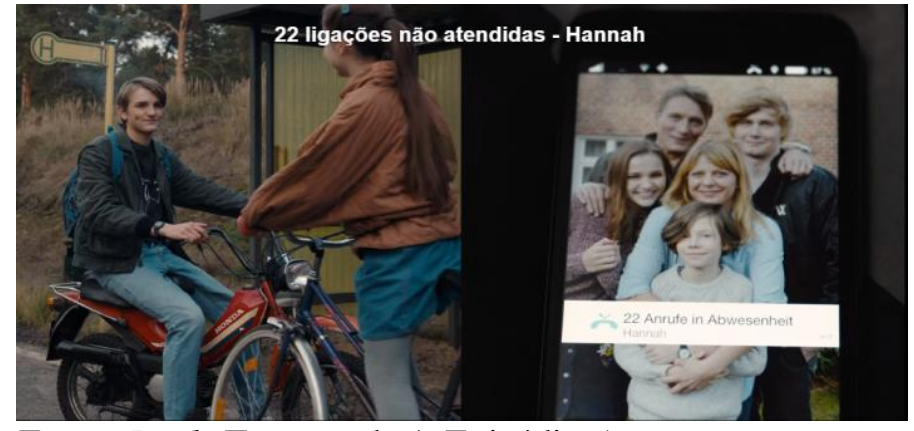

Fonte: Dark, Temporada 1, Episódio 5.

Nesse mesmo capítulo o conceito de eterno retorno de Nietzsche aparece pela primeira vez de forma explícita. A ideia é apresentada em um diálogo entre Charlotte e Ulrich sobre os fatos ocorridos na cidade e a estranha ligação reiterada entre o que aconteceu no passado.

Ulrich: Sabe por que eu me tornei um policial? Quando meu irmão desapareceu cometeram todos os erros possíveis. O encarregado era um bêbado imbecil. E eu...jurei que faria tudo diferente. Que faria as coisas certas. Que não seria um idiota incompetente como ele. Isso foi há 33 anos. E agora olhe para mim. Sou uma piada. Eu traio minha esposa. Meu filho sumiu e eu não posso fazer nada. 33 anos. Tudo está igual. Mas agora, eu sou o idiota incompetente.

Charlotte: Já ouviu falar do ciclo de 33 anos?

Ulrich: Não

Charlotte: Nosso calendário está errado, o ano não têm 365 dias. Estamos sempre fora do ritmo. Mas a cada 33 anos tudo volta ao normal. As estrelas, os planetas, todo o universo fica exatamente na 
mesma posição. É o ciclo solar-lunar. Meu avô era obcecado pelo Big Bang, Big Crunch, o Eterno Retorno de Nietzsche. Quando eu era jovem, pensava que havia algo de errado com Winden. Tenho a mesma sensação agora. Que tudo se repete. Que tudo isso já aconteceu antes. Como um grande déjà vu (DARK, 2017, Temporada 1, Episódio 5, grifo nosso).

\section{Figura 11 - Ulrich ouve Charlotte falar sobre o Eterno Retorno}

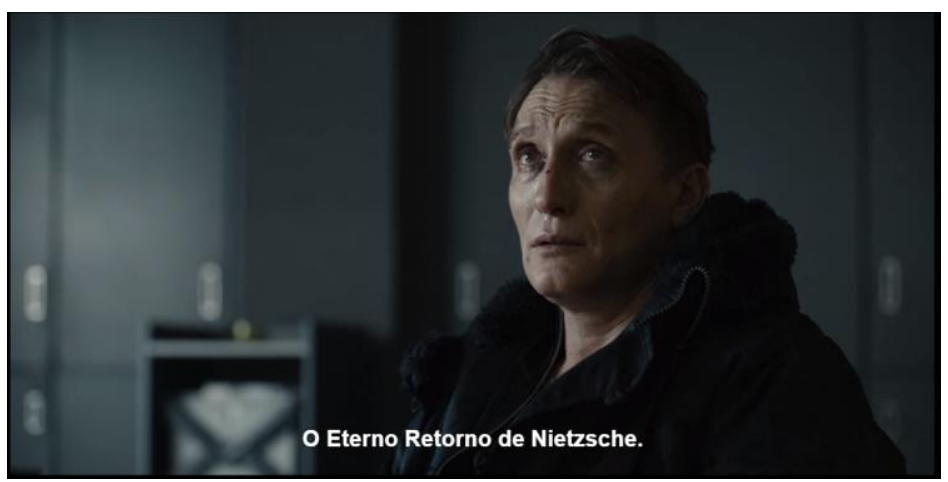

Fonte: Dark, Temporada 1, Episódio 4.

Ao se tornar aquele que mais criticava e perceber a repetição dos ciclos, Ulrich atenta à ideia apresentada por Charlotte. A chefe de polícia fala sobre o livro do avô que une o conceito de Eterno Retorno a pressupostos científicos (Figura 11). As ideias do familiar de Charlotte, H.G.Tannhaus, são apresentadas em um diálogo entre o relojoeiro e o Estrangeiro no oitavo capítulo da temporada (Figura 12).

[...] Estrangeiro: O senhor escreve sobre o Eterno Retorno de Nietzsche, um universo que se expande e colapsa. Um universo que sempre se repete. (Mostra o livro Uma jornada através do tempo, de autoria do próprio Tannhaus)

Tannhaus: Fazia tempo que não via um desses. Existem apenas 500 cópias no total.

Estrangeiro: Escreveu sobre os ciclos solar e lunar, que sincronizam a cada 33 anos.

Tannhaus: Do ponto de vista cósmico, sim. A cada 33 anos a rota da Lua se sincroniza com a do Sol. Mas o 33...é mais do que isso. Está em todo lugar. Jesus fez 33 milagres. Existem 33 litanias dos anjos. Há 33 cantos no purgatório de Dante e 33 no paraíso [...] (DARK, 2017, Temporada 1, Episódio 8). 
Figura 12 - Enquanto narra sobre o Eterno Retorno, imagens de outros personagens são apresentadas. Na imagem, Helge Doppler em 1953

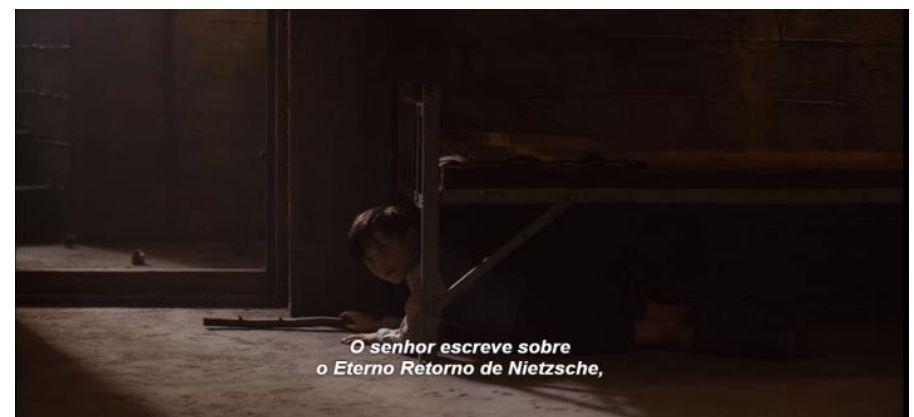

Fonte: Dark, Temporada 1, Episódio 8.

A série associa a ideia nietzschiana a conceitos científicos e cosmológicos que apontam para o retorno e a repetição de todas as coisas. Insatisfeitos com o curso temporal, porém, alguns personagens tentam alterar o que passou ou o que virá, justamente por não aceitarem o estado presente, que para Nietzsche é justamente o caminho para uma vida em plenitude.

Um discurso semelhante ocorre entre Jonas Kahnwald e sua avó, Ines Kahwald. Após ter viajado pelo tempo e ter visto que o amigo desaparecido se transformaria no pai, Jonas, em negação, lamenta-se da relação incestuosa que tudo aquilo provocara e discute com a familiar. Isso ocorre no décimo capítulo da narrativa.

$[\ldots]$

Jonas: Se a senhora sabia, por que não impediu?

Ines: Eu não sabia que ele ia se matar.

Jonas: Mas podia ter salvado Mikkel! Agora tenho outra avó que é a diretora da minha escola. O marido dela, que transa com minha mãe, procura o filho, que é meu pai! Há alguns dias, eu beijei a minha tia. $\mathrm{E}$ o mais louco é que não há nada de errado com eles. Eles estão bem. Sou eu que estou errado.

Ines: Acho que as coisas por mais anormais ou estranhas que pareçam acontecem por um motivo. Quem somos nós para brincarmos de Deus? O passado é passado. Mas você... vive no presente. Quem sabe o que o futuro trará?

Jonas: Só quero que tudo volte ao normal (DARK, 2017, Temporada 1, Episódio 10, grifos nossos). 
Figura 13 - Jonas discute com a avó Ines Kahnwald

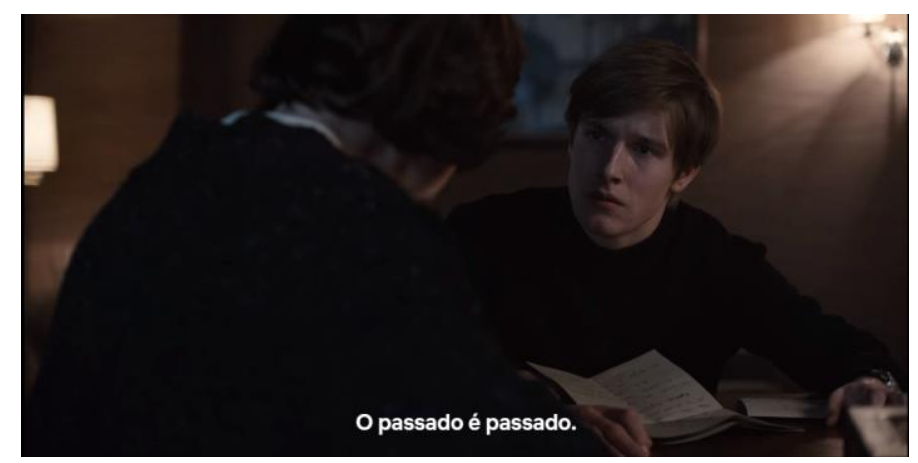

Fonte: Dark, Temporada 1, Episódio 10.

Do diálogo supracitado, destacaremos os grifos. Ao relatar que incorre em errado após ter visto o passado e entender o encadeamento trazido pela memória ao tempo presente, Jonas sente o espírito sobrecarregado com o peso de um destino que ele parece querer não suportar. A fortuna que lhe é imposta coloca o passado do jovem, ou a sua história, como algo que atravanca o curso das coisas em seu devir.

O pensamento de Ines (Figura 13), diferentemente do de Jonas, parece ir ao encontro do de Nietzsche (2003). A avó do rapaz diz acreditar na vida mesmo que esta esteja cheia de aspectos "anormais", "estranhos", ou que o destino pareça terrível. De forma bastante sutil, visto que o comentário de Ines é ínfimo em relação a todo o contexto da série, Dark parece revelar, ao menos na primeira temporada e muito subliminarmente, uma saída para a ruminação ressentida: a aceitação de que o "passado é passado" e que ainda que o fardo se torne monstruoso, devemos viver no presente, já que não há possibilidade de sabermos acerca do futuro.

\section{Considerações Finais}

Uma mudança fundamental começa a se desenvolver no Ocidente no que referese à compreensão do mundo e da realidade, argumenta Byung-Chul Han. Para o filósofo coreano, essa modificação está associada ao entretenimento, que se eleva hoje a um novo paradigma, a uma nova "fórmula do ser, que decide sobre o que é passível de pertencer ao mundo e o que não é, sim, sobre o que é em geral. Assim, a realidade se apresenta ela mesma como um efeito especial do entretenimento" (HAN, 2019, p.9). 
Se na contemporaneidade, o entretenimento ocupa um papel importante no imaginário e nas formas de percepção do mundo, indo além do fenômeno do tempo livre e vinculando-se ao sistema social, podemos dizer que o entretenimento é parte do sentimento "trágico-lúdico" de que trata Maffesoli (2003). O poder que entretém associase, sobretudo, ao caráter de efemeridade do instante-presente, que parece ser uma das marcas da atualidade.

Portanto, na medida em que o entretenimento está associado ao cotidiano e este a um caráter repetitivo e cíclico, Dark, enquanto produto de seu tempo submetido às condições de produção vigente, manifesta essa cosmovisão cíclica, ao mesmo tempo que a produz.

Observa-se, por meio da análise comparativa entre as ideias de Nietzsche e o enredo da série Dark, um alinhamento que parece permear o discurso e o roteiro da narrativa. Os conceitos nietzschianos de Ressentimento e Eterno Retorno são extemporâneos e apontam para uma reverberação ascendente dessa filosofia do século XIX no contexto hodierno, seja no campo epistemológico e filosófico, seja na psicanálise, na literatura, no cinema e, mais recentemente, na ficção seriada, como procuramos mostrar.

Ratificamos a hipótese de que a série parece levantar questionamentos que buscam contribuir para que o espectador possa encontrar caminhos dentro de si que fortaleçam seu Ser, levando-nos a entender o sofrimento "sem renegá-lo nem maldizê-lo, mas acolhendo-o e integrando-o como condicionante de toda grandeza de que o ser humano pode ser capaz em sua existência” (NIETZSCHE, 2000, p. 69).

As muitas perguntas que Dark pode suscitar deixam em aberto as inúmeras possibilidades de formas de ver, pensar e sentir o mundo; e apontam para o aspecto de que o merecido sucesso que a série conquistou, pode estar de algum modo relacionado com a maneira como vivemos hoje nossa temporalidade.

\section{Referências}

AZUBEL, Larissa. Uma série de contos e os contos em série: o imaginário pós-moderno em Once Upon a Time. 2017. Tese (Doutorado em Comunicação Social) - Programa de PósGraduação em Comunicação Social da Pontifícia Universidade Católica do Rio Grande do Sul. Porto Alegre, 2017. 
BITTENCOURT, Renato Nunes. A tipologia do ressentimento em Dostoievski e Nietzsche. Revista Húmus, São Luiz, v. 2, n. 2, p. 73-91, 2011. Disponível em: http://www.periodicoseletronicos.ufma.br/index.php/revistahumus/article/download/1632/1294. Acesso em: 30 set. 2020.

DARK. (Temporada 1). [Série] Direção: Baran bo Odar. Roteiro: Baran bo Odar; Jantje Friese. Produção: Baran bo Odar, Jantje Friese, Wiederman \&amp; Berg Filmproduktion, Justyna Musch, Quirin Berg, Max Wiedermann. Alemanha: Netflix, 2017. Streaming, cor. 10 episódios

DIAS, Rosa Maria. Nietzsche, vida como obra de arte. Rio de Janeiro: Civilização Brasileira, 2011.

GIACÓIA JÚNIOR, Oswaldo. Nietzsche como psicólogo. São Leopoldo. Editora da Unisinos, 2001.

HAN, Byung-Chul. Bom entretenimento: uma desconstrução da história da paixão ocidental. Tradução de Lucas Machado. - Petrópolis, RJ: Vozes, 2019

JOST, François. Do que as séries americanas são sintoma? Porto Alegre: Sulina, 2012.

KEHL, Maria Rita. Ressentimento. São Paulo: Casa do Psicólogo, 2011.

MAFFESOLI, Michel. O instante eterno: o retorno do trágico nas sociedades pós-modernas. Tradução: Rogério de Almeida, Alexandre Dias. São Paulo: Zouk, 2003.

MECA, Diego Sánchez. Nietzsche ou a eternidade do tempo. Caderno Nietzsche, São Paulo, v. 33, p. 181-196, 2013.

NIETZSCHE, Friedrich. A gaia ciência. Tradução: Antônio Carlos Braga. São Paulo: Escala, 2013.

NIETZSCHE, Friedrich. Assim falava Zaratustra. Tradução: Ciro Mioranza. São Paulo: Escala Educacional, 2006.

NIETZSCHE, Friedrich. Ecce homo. Tradução: Marcelo Backes. Porto Alegre: L\&PM, 2003.

NIETZSCHE, Friedrich. Genealogia da Moral: uma polêmica. Trad. de Paulo César de Souza. São Paulo: Companhia das Letras, 2000.

NIETZSCHE, Friedrich. Obras incompletas. Tradução: R. R. Torres. 2. ed. São Paulo: Abril Cultural, 1978. (Os pensadores).

PAREDES, Lenin Vladimir. El eterno retorno: análisis de la concepción temporal en la serie Dark de Netflix. PAAKAT: Revista de tecnologia y sociedade, v. 9 n.16. Guadalajara. mar. 2019.

PASCHOAL, Antônio Edmilson. Nietzsche e During: ressentimento, vingança e justiça. Revista Dissertatio, Pelotas, v. 33, n. 2, p. 147-172, 2008. Disponível em: https://periodicos.ufpel.edu.br/ojs2/index.php/dissertatio/article/view/8721 Acesso em: 04 ago. 2020. 
SAFRANSKI, Rudüger. Nietzsche: biografia de uma tragédia. Tradução: Lya Luft. São Paulo: Geração Editorial, 2011.

VALENZUELA, Sandra Trabucco. A fragmentação na série Dark: o ser, o espaço e o tempo. In: SILVA, Lourdes Ana Pereira; GUARANHA, Manoel Francisco; BASEIO, Maria Auxiliadora (Org.). Identidades ficcionais: narrativas literárias e televisivas. Covilhã: LabCom Comunicação \& Artes, 2020, v. 1, p. 149-166.

VARGAS, Herom; CORRÊA, Angela Miguel. Recapitulações na série original Netflix Dark: alterações na estrutura narrativa tradicional televisual. Revista lationoamericana de la comunicación, v. 17, p. 246-257, 2019. 